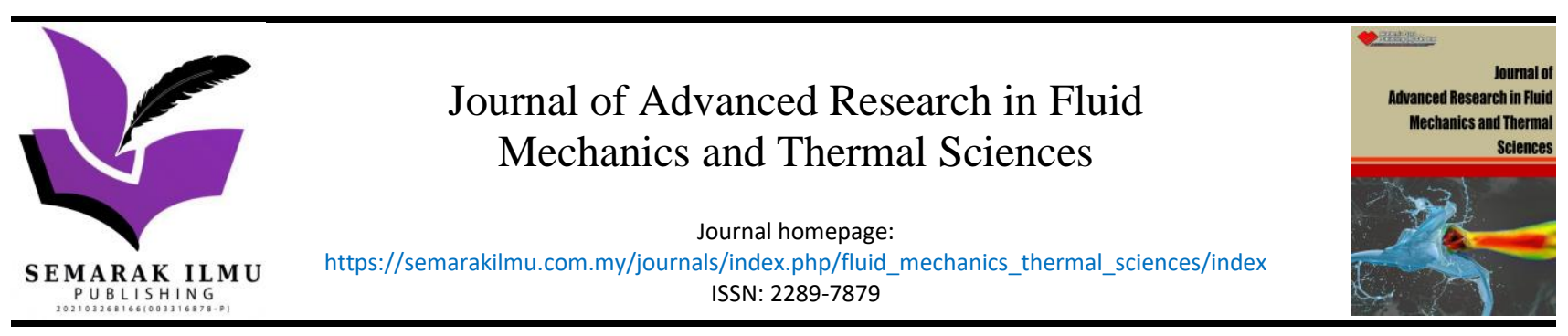

\title{
Discrete Phase Modelling of Sediment Transport and Scouring of Suspended Particles in Dam Spillway
}

\author{
Nazirul Mubin Zahari ${ }^{1,}{ }^{*}$, Mohd Hafiz Zawawi ${ }^{1}$, Lariyah Mohd Sidek ${ }^{2}$, Fei Chong $\mathrm{Ng}^{3}$, Mohamad Aizat \\ Abas $^{3}$, Farah Nurhikmah ${ }^{1}$, Muhammad Naqib Nashrudin ${ }^{3}$ \\ Department of Civil Engineering, College of Engineering, Universiti Tenaga Nasional, Selangor, Malaysia \\ Institute of Energy Infrastructure (IEI), Universiti Tenaga Nasional (UNITEN), 43000 Kajang, Selangor, Malaysia \\ School of Mechanical Engineering, Universiti Sains Malaysia, Engineering Campus, Nibong Tebal, 14300, Penang, Malaysia
}

ARTICLE INFO ABSTRACT

\section{Article history:}

Received 30 May 2021

Received in revised form 25 August 2021

Accepted 9 September 2021

Available online 26 October 2021

\section{Keywords:}

Dam reliability analysis; discrete phase model (DPM); finite volume method (FVM); sedimentation; particle image velocimetry (PIV); suspended particles

\begin{abstract}
One of foremost issue arise in the dam management and dam reliability assessment is the sedimentation of suspended particles. Sedimentation affected the energy production and efficiency, storage, discharge capacity, and flood attenuation capabilities. In this paper, the sediment transport and scouring in the dam spillway structure was modelled using finite volume method (FVM) based software, ANSYS. The trajectory of suspended particles in the water flow was formulated based on the discrete phase model (DPM). To access the simulation model, particle image velocimetry (PIV) experiment using scaleddown dam spillway model was conducted. The discrepancy between the findings attained from simulation and PIV experiment is less than $4.89 \%$, inferred the numerical model was acceptable. It was found that the maximum scouring rate and maximum deposition rate are respectively $4.20 \times 10-9 \mathrm{~kg} / \mathrm{s}$ and $2.00 \times 10-6 \mathrm{~kg} / \mathrm{s}$. As such, it was empirically approximated the dam maintenance should be scheduled once every 8.9 years, based on sole consideration on resolving the scouring and deposition of suspended particles. This work demonstrated the viability of DPM based numerical simulation in study the fluidparticle interaction of sediment transport problem, particularly for the application of dam reliability.
\end{abstract}

\section{Introduction}

Dam is a vital infrastructure for both water storage and hydroelectric generation, which is essential to fulfil both domestic and industrial water and electricity needs. Regular maintenance on dam structure is necessary to prevent disastrous dam failure events, potentially lead to casualties, financial losses, and ecosystem damages. Accordingly, there are various researches being conducted to analyse the structural reliability of dam and later devise suitable mitigation and maintenance protocols [1]. Most of reported dam reliability researches emphasize on the fluid-structure interaction (FSI) phenomenon of focused dam structures, for instance, spillway [2], radial gate [3,4], downstream sector [5] and reservoir bank [6]. These past works evaluated the existing implemented

\footnotetext{
* Corresponding author.

E-mail address: mubinzahari@gmail.com
}

https://doi.org/10.37934/arfmts.88.2.3849 
operating conditions on the structure, from the point views of stress and deformation and failure to justify the potential failures arise.

Sediment transport is the movement of suspended particles at the bottom bed of downstream of dam spillway along the water flow. It is vital to study the sediment transport in dam structure for the determinations of erosion and deposition, which both are detrimental to the dam structural reliability. In the past studies, the sediment transport in dam structure was numerically simulated. For instance, the sediment pulse model was applied to simulate the landslide in Navarro River, California [7]. Additionally, the developed dam removal express assessment models (DREAM) was proposed to study the sediment transport problem [8]. There is an analytical approach to compute the transport of coarse and fine sediments which also accounting the grain size distribution [9].

To enhance the veracity of sediment transport and scouring analyses, comprehensive research methodologies were adopted. A combination of empirical formulations, pressure fluctuationserodibility index and numerical simulations was applied to solve the scouring problem in dam [10]. Another study seen the combination of field observations, mathematical model tests, and several hydraulic scale models [11]. The maximum scour depth can be predicted based on the empirical and semi-empirical equations [12].

It was reported that the discrete element method (DEM) simulation can capture the physics of granular characteristics of suspended sediment particles but at the expense of long computational time [13]. As such, the discrete phase model (DPM) was proposed to reduce the computational speed [14]. DPM has seen various applications in the computational fluid dynamics (CFD) simulation, for instances hydraulic engineering, thermal engineering and electronic packaging $[15,16]$. To date, there is no literature that reported the use of DPM in simulating the sediment transport and scouring problems.

This paper presents the discrete phase model (DPM) simulation on the sediment transport and scouring in a dam spillway, as part of dam reliability study. The numerical model was validated with particle image velocimetry (PIV) experiment based on scaled-down physical model of the investigated dam spillway. The sediment transport of suspended particles at the downstream of spillway were visualized and analyzed to determine the scour rate.

\section{Numerical Simulation}

This section provided the details of numerical simulation of the dam spillway flow with suspended sediment particles using ANSYS software, which utilizing the fluid-structure interaction (FSI) approach with discrete phase model (DPM) for the formulation of sediment particles. FSI is characterized by the interactions between a deformable or moving structure and the surrounding or internal fluid flow, while DPM enables the precise prediction of the trajectory particles.

\subsection{Governing Equations}

The fluid flow in the current simulation work was governed by the Navier-Stokes equation which involves both the conservation of mass and momentum, respectively given by the continuity equation and momentum equation as follows

$\frac{\partial \rho}{\partial t}+\nabla(\rho u)=0$

$\frac{\partial(\rho \boldsymbol{u})}{\partial t}+\nabla(\rho \boldsymbol{u} \cdot \boldsymbol{u})=-\nabla P+\nabla \tau+\rho g$, 
where $\rho$ denotes the density of the fluid, $\boldsymbol{u}$ is the flow velocity, $\tau$ is the shear stress, and $\mathrm{g}$ is the gravitational acceleration. Moreover, the model is based on two phase interactions of water and air, with the flow front was tracked by the volume of fluid (VOF) model. Both the phases are distinguished by the volume fraction, $f$, in the range of 0 to 1 , governed by the transport equation as follows

$\frac{\partial \rho}{\partial t} f+u \nabla f=0$

Meanwhile, the sediment particles suspended in the continuum flow phase was governed by the force balance equation. The trajectory and tracking of the suspended particles in the fluid are associated with the mass and other forces exerted on each of the particles was given by

$\frac{\partial u_{p}}{\partial t}=F_{D}\left(u-u_{p}\right)+g_{x} \frac{\left(\rho_{p}-\rho\right)}{\rho_{p}}+F_{x}$

where the first term $F_{D}\left(u-u_{p}\right)$ is the drag force associated with the velocities of fluid and particles (respectively denoted as $u$ and $u_{p}$ ), $\mu$ is the dynamic viscosity of the fluid, $\rho_{p}$ is the density of suspended particle, $\rho$ is the density of fluid and $g_{x}$ is the $x$-component gravitational acceleration. The additional force term, $F_{x}$, is related to the mass, acceleration, and pressure gradient in the fluid based on the consideration that $\rho>\rho_{p}$, given by

$F_{x}=\frac{\rho}{\rho_{p}} u_{p}\left(\frac{\partial u}{\partial x}\right)$

For the multiphase flow, the virtual mass effect that occurs when secondary phase $p$ accelerates relative to primary phase $q$ can be optionally included. The inertia of the primary-phase mass encountered by the accelerating particles (or droplets or bubbles) exerts a virtual mass force on the particles. The virtual mass force is defined as

$\vec{F}_{v m}=\frac{1}{2} \alpha_{p} \rho_{q}\left(\frac{\mathrm{d}_{q} \vec{v}_{q}}{\mathrm{~d} t}-\frac{\mathrm{d}_{p} \vec{v}_{p}}{\mathrm{~d} t}\right)$

where the differentiate term $\frac{\mathrm{d}_{q}}{\mathrm{~d} t}$ denotes the phase material time derivative of the form of

$\frac{d_{q}(\phi)}{d t}=\frac{\partial(\phi)}{d t}+\left(\vec{v}_{q} \cdot \nabla\right) \phi$

The virtual mass force, $\vec{F}_{v m}$, was added to the right-hand side of the momentum equation for the both phases

$\vec{F}_{v m, q}=-\vec{F}_{v m, p}$

Nonetheless, the virtual mass effect is significant when the secondary phase density is considerably smaller than the primary phase density, i.e. transient bubble column. The suspended sediment particles would suspend on the water due to buoyancy and flow move along with the continuum streamlines of water. This would establish a two-way multiphase fluid-particle interaction $[15,16]$. 


\subsection{CAD Geometrical Model}

The dam spillway consists of two parts, for instance the upstream section and downstream section. To reduce the complexity of spillway geometry and thus to enable the practicality of subsequent particle image velocimetry (PIV) experiment, the dam spillway model was proportionally scaled down based on the actual dam spillway with a scale of 1: 40 . This scaling was justified based on the guideline of scaling limit proposed on flow system. Moreover, the existence of past experimental works that based on scaled-down dam model had further affirmed the current choice of scaling of dam model.

The CAD geometry of dam spillway model as generated using SolidWorks software was depicted in Figure 1 (a). Figure 1 (b) shows the fabricated scaled-down physical model of dam spillway made of clear transparent Perspex for the subsequent PIV experiment.

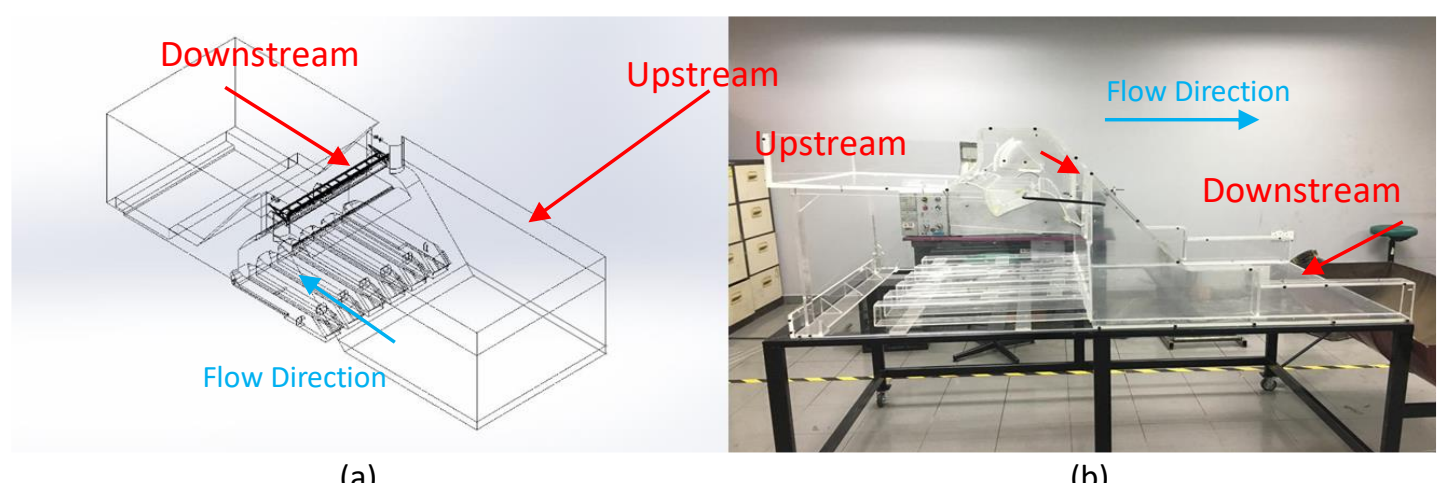

(a)

(b)

Fig. 1. (a) CAD geometrical model and (b) fabricated scaled-down physical model for the investigated dam spillway

\subsection{Mesh, Boundary Condition and Setups}

The schematic and the mesh model of the scaled-down dam spillway model were shown in Figure 2. The mesh developed for the current model is based on the unstructural tetrahedrons mesh using optimized mesh sizing. Pressure-based solver was chosen, with the semi-implicit method for pressure linked equations and second-order upwind algorithm schemes were adopted for both the coupling of pressure-velocity and spatial discretization respectively. A fixed time step of $0.01 \mathrm{~s}$ was chosen for the simulation. The numerical fluid domain comprised of air, water and sediment particles. The tracking of multiphase of air and water was based on the implicit multiphase model, with air being the primary phase and water as the secondary phase.

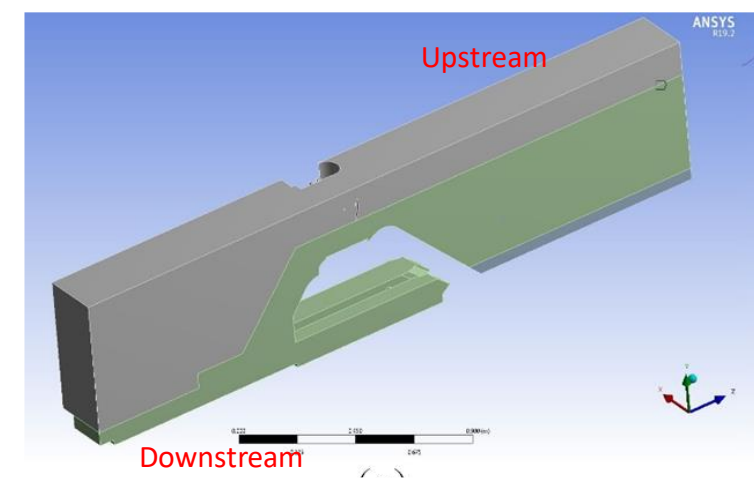

(a)

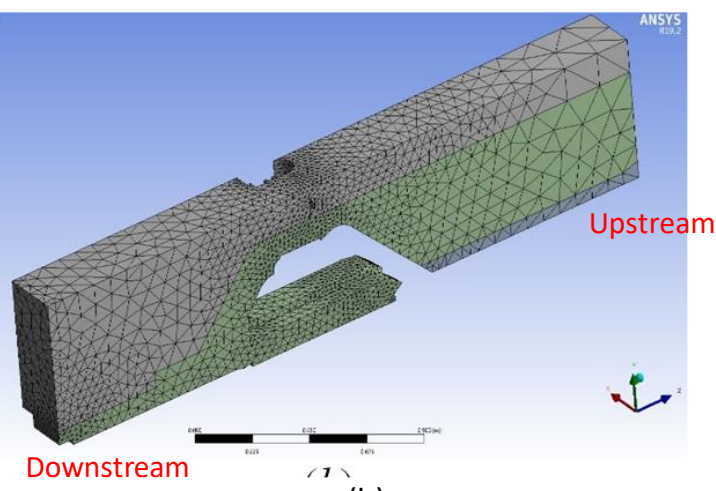

(b)

Fig. 2. (a) Fluid domain surrounding the dam spillway structure and (b) the meshed fluid domain 
Figure 3 depicted the boundary conditions imposed on the fluid domain, including inlet, outlet and wall. For the mixture phase of the inlet, velocity inlet $\mathrm{BC}$ is used to define the velocity and scalar properties of the flow. The velocity of the water flow into the inlet is set at $0.0075 \mathrm{~m} / \mathrm{s}$ to ensure that it is nearly negligible and does not have a huge effect on the fluid flow. Meanwhile, a no-slip wall condition is imposed to ensure that the wall-fluid velocity is $0 \mathrm{~m} / \mathrm{s}$. Moreover, the pressures at the inlet and the outlet are equal to the atmospheric pressure, which is $0 \mathrm{~Pa}$ (gauge) [17].

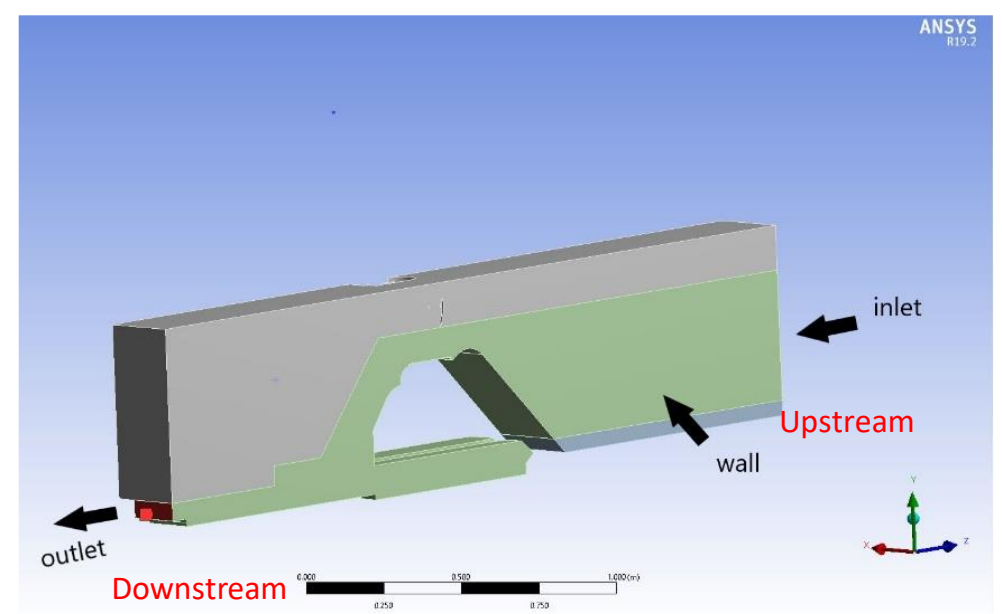

Fig. 3. The boundary conditions imposed on the fluid domain

\section{Particle Image Velocimetry (PIV) Experiment}

Particle image velocimetry (PIV) is a non-intrusive optical method that can be used to determine the instantaneous vector measurement throughout the cross-sectional view. The motion is followed using small tracer particles of polyamide seeding particles. The LED light will illuminate the tracer particles by creating a thin laser light sheet. Subsequently, the image will be captured using a camera specifically at the target area. On the basis of the positions of these tracer particles at two different instances of time, we can obtain the particle displacement to infer the flow velocity field. The velocity vector of the fluid through the tracer particles is computed on the basis of the instantaneous displacement of the tracer particle, $\Delta x$ between two consecutive light pulses separated by an interval of $\Delta t$, as follows [18-20]

$V_{P I V}=\frac{\Delta x}{\Delta t}$

Figure 4 and Figure 5 depicted the actual and the corresponding schematic outline PIV experimental setup for the water flow in scaled-down dam spillway model. A camera was placed perpendicularly to the laser to record the flow of water from the side of the water tank. Laser was used to produce a thin illuminated sheet which track the polyamide particles. Subsequent the flow experiment, two consecutive images were extracted from the recording and pre-processed to remove noises. PIV lab software was used to analyze the images to plot the velocity vector contours. 


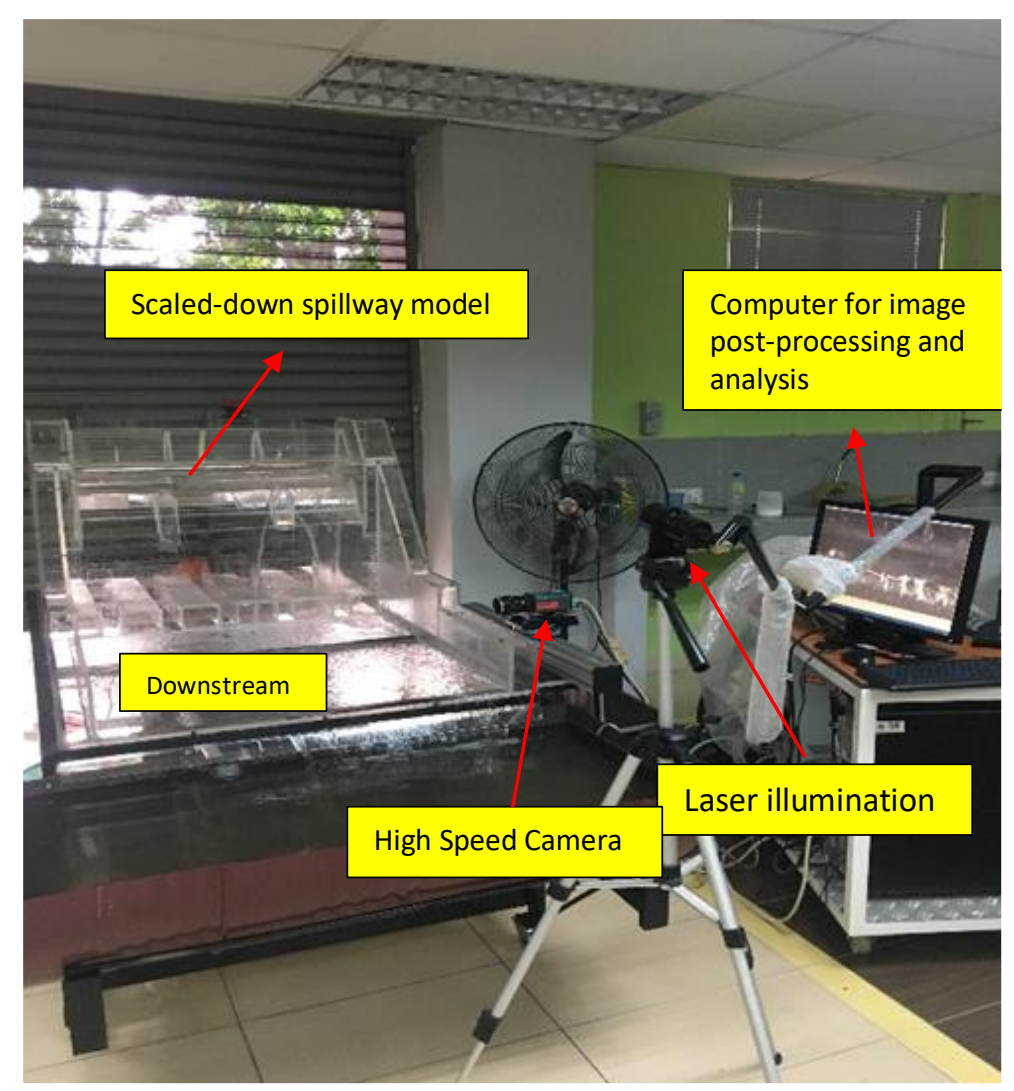

Fig. 4. PIV experiment setup

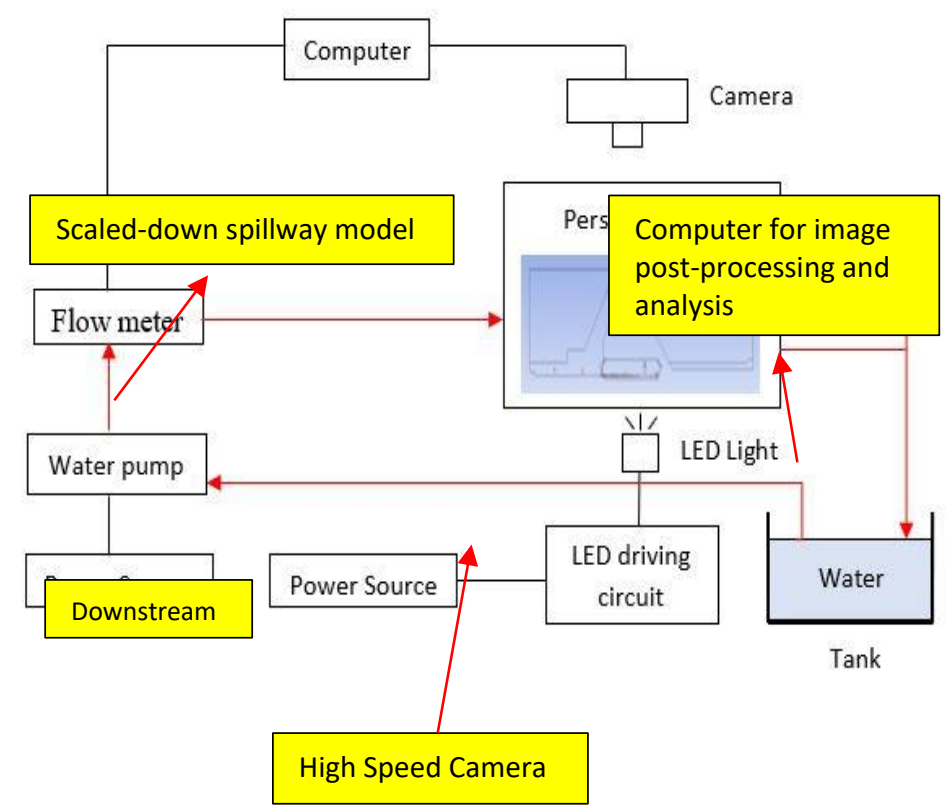

Fig. 5. Schematic overview of the experimental PIV setup

\section{Results}

\subsection{Validations}

Figure 6 depicts the four points of interest associated to the numerical-experimental comparison of velocity contours in Table 1. It was found that discrepancy between the findings obtained from numerical simulation and PIV experiment is not exceed $4.89 \%$, thus affirming the veracity of 
numerical model. Particularly, at high flow velocity, the flow vortex was observed at point 2 where the water flow drops from the upstream. At the point 4, laminar flow streamlines were exhibited as the flow velocity is stable and low.

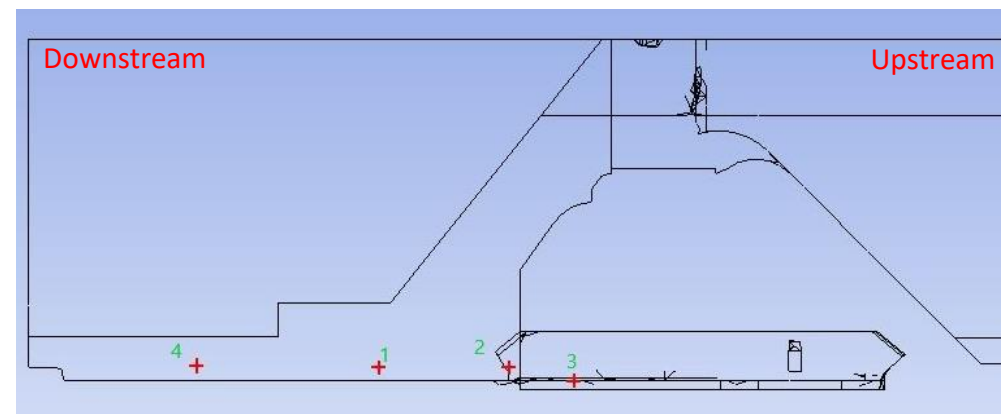

Fig. 6. The locations of four points of interests (1, 2, 3 and 4) on the dam spillway

Table 1

Comparison between numerical and experimental flow velocity contours at five distinct points of interest

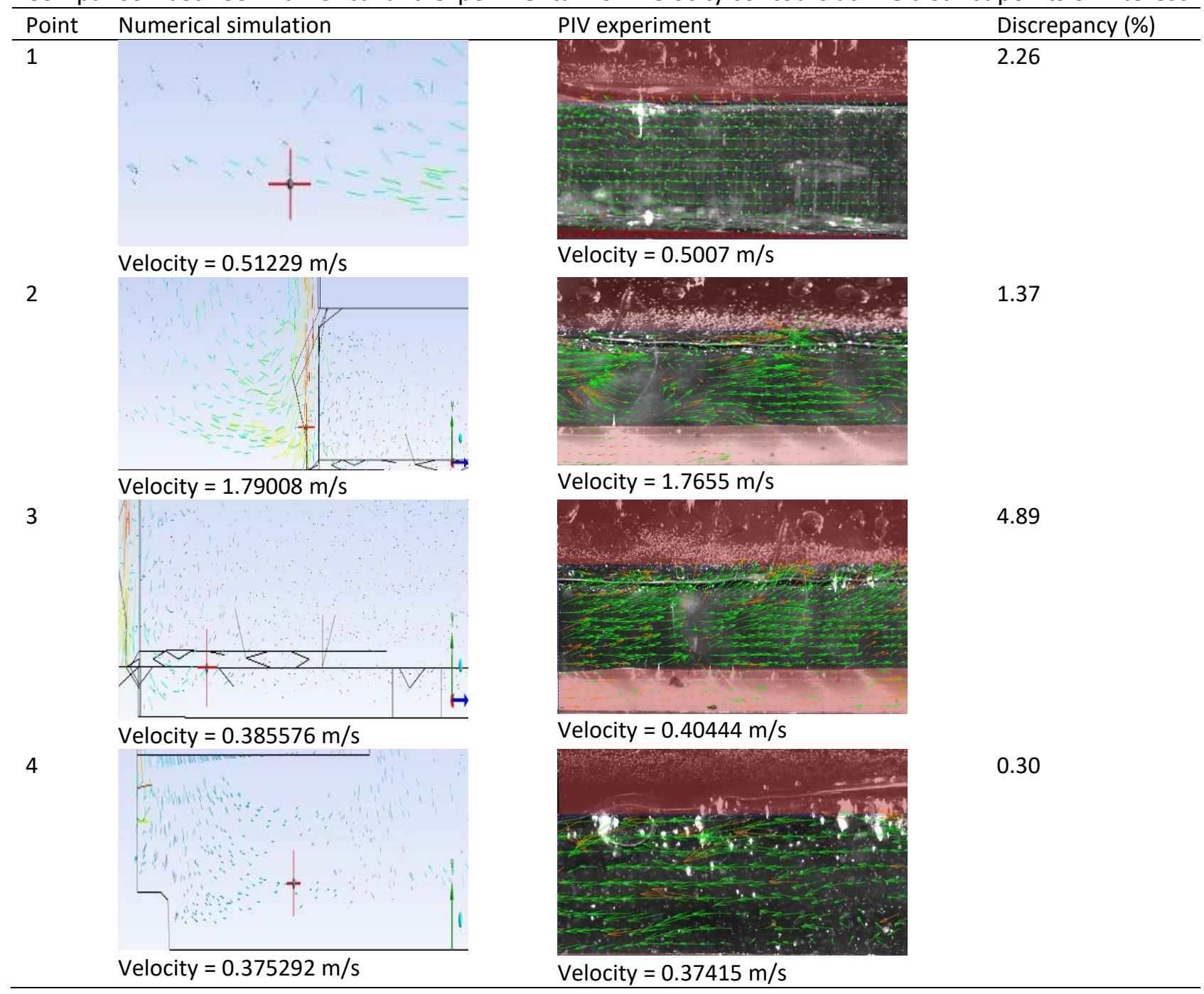




\subsection{Pressure and Velocity}

Table 2 gave the pressure and velocity of spillway flow at the times of 0.5 s, 1.0 s, 1.5 s, and 2.0 s. The simulation showed that the hydrostatic pressure built up on the water at the upstream, which the pressure increases with the water depth. The flow downstream has lower pressure due to the high velocity of water in accordance to the Bernoulli's principle. Additionally, the velocity vectors are similar to the predicted vectors. Velocity is highest in the region of transition from upstream to downstream. The free stream in the upstream region has low velocity due to the low velocity from the inlet. Observation can be made on velocity magnitude over time. The velocity remains the same as time increases, inferring stable flow regime.

\section{Table 2}

Pressure contours and velocity vectors obtained from the numerical simulation

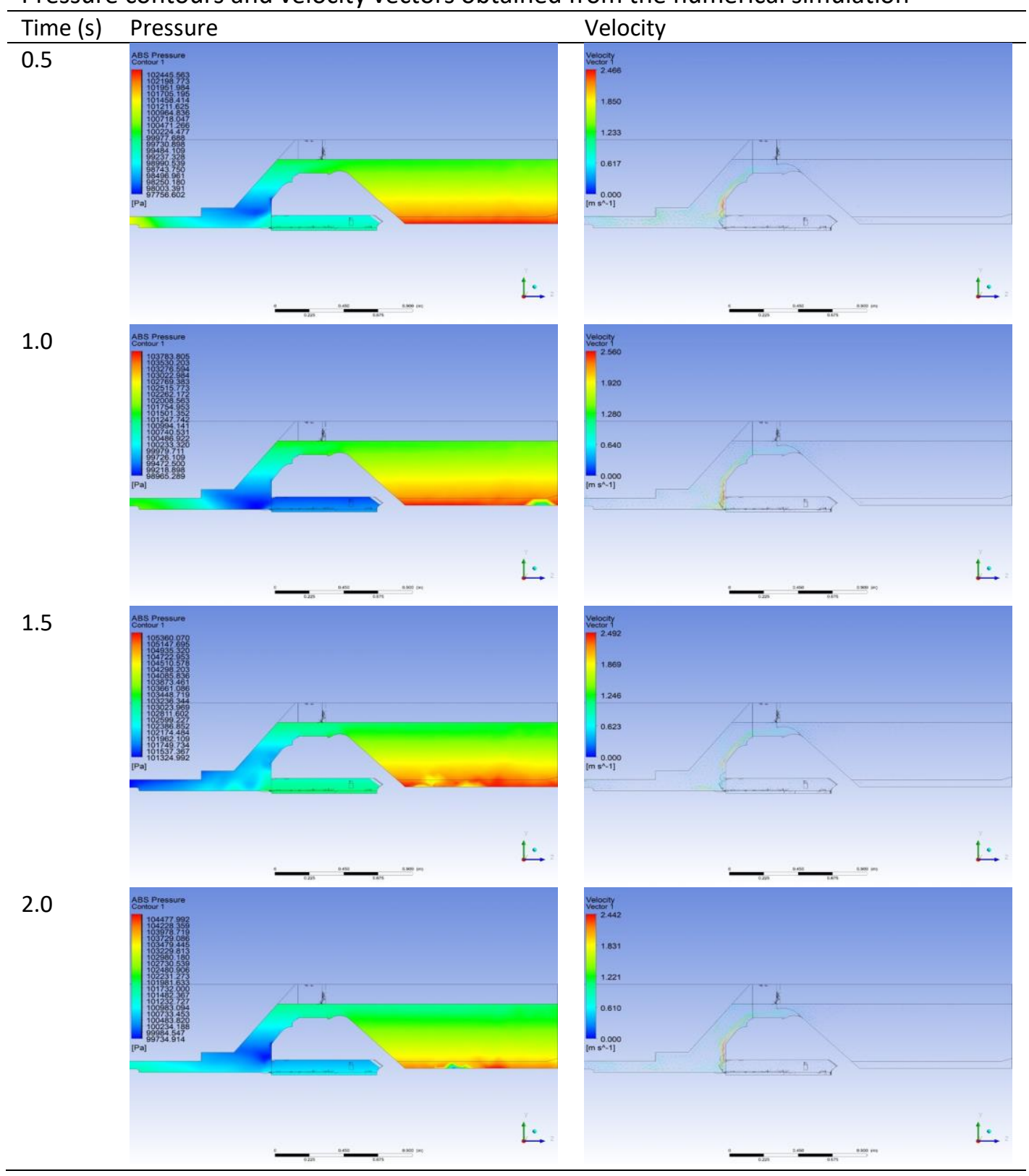




\subsection{Particle Track and Scouring Rate}

Table 3 showed the particle track of sediment particles at different time. At $0.5 \mathrm{~s}$, most of the particles were in still position with few particles being displaced. In the region near the inlet, the particles start to move as water flows in. At $1 \mathrm{~s}$, about half of the particles start to displace along the water flow, such that the particles suspended in the water while exhibited oscillatory motion in the vertical direction. At $1.5 \mathrm{~s}$, there are more sediment particles being disrupted. However, some of the particles near the dam were left uninterrupted. Most of the particles are lifted from the bottom of the model. The particles are dispersed because of the continuous water flow. Finally at $2 \mathrm{~s}$, all the particles were moved as an interaction result due to the water flow from inlet.

Table 3

Sediment particle tracks at the bottom of dam spillway

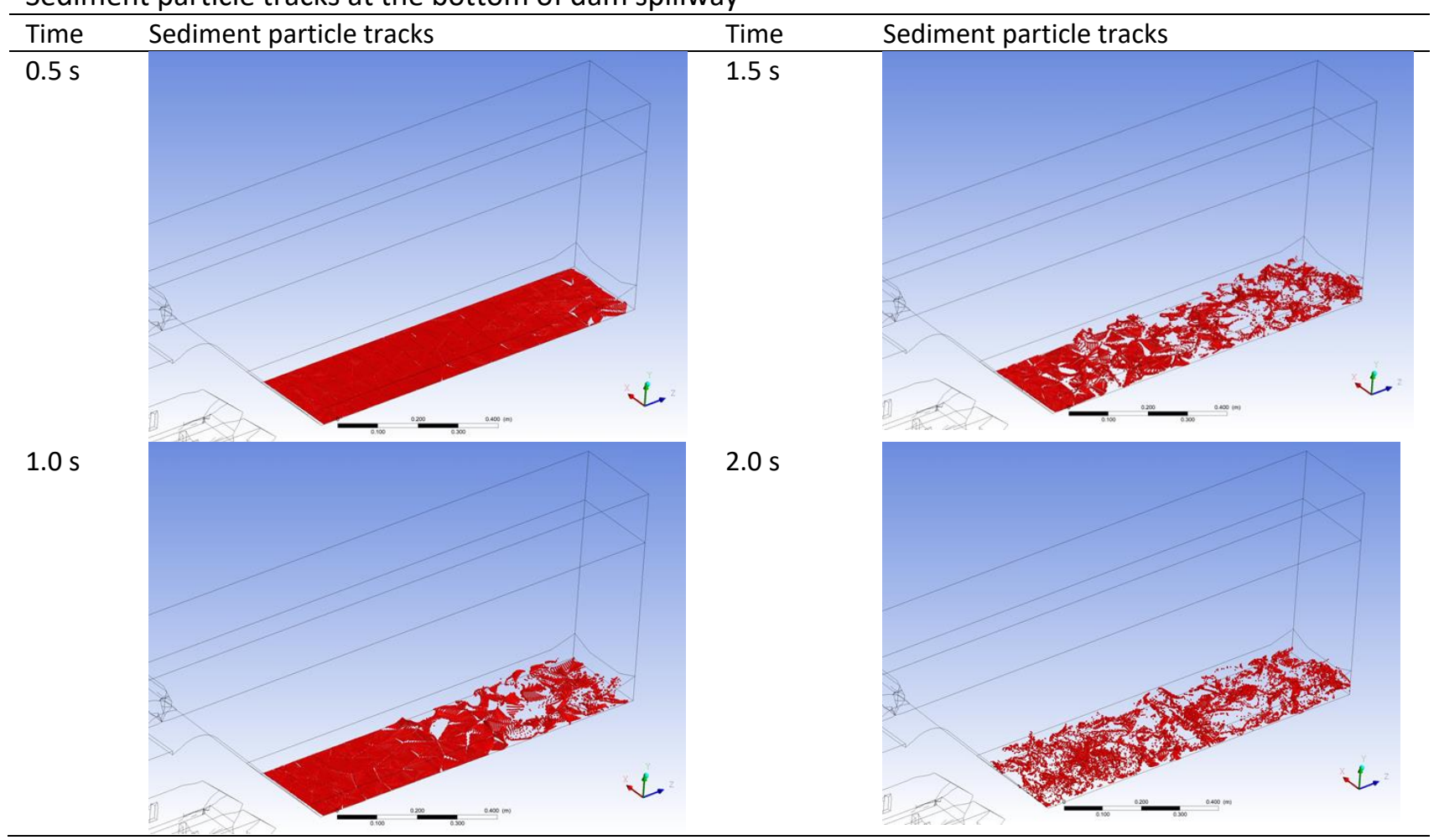

The total masses and numbers of particles over time at the four different regions follow the order $A, B, C$, and D, as depicted in Figure 7. The plots in Figure 8 and Figure 9 gave the sediment mass and sediment mass loss over time respectively. It was found that both the total mass and number of particles are decreasing over time, consistent to the sediment transport phenomenon which align to the observation of sediment particle tracks in Table 3.

Region $A$ has the highest number of particles since it is nearest to the dam structure. Thus, a huge number of sediments here will harm the bottom structure of the dam. This condition can also decrease the water level of the reservoir. Table 3 showed that the sediment particles tend to move toward Region A, which can also be observed from the gradual total mass loss over time at the different regions given in the plots of Figure 8. 


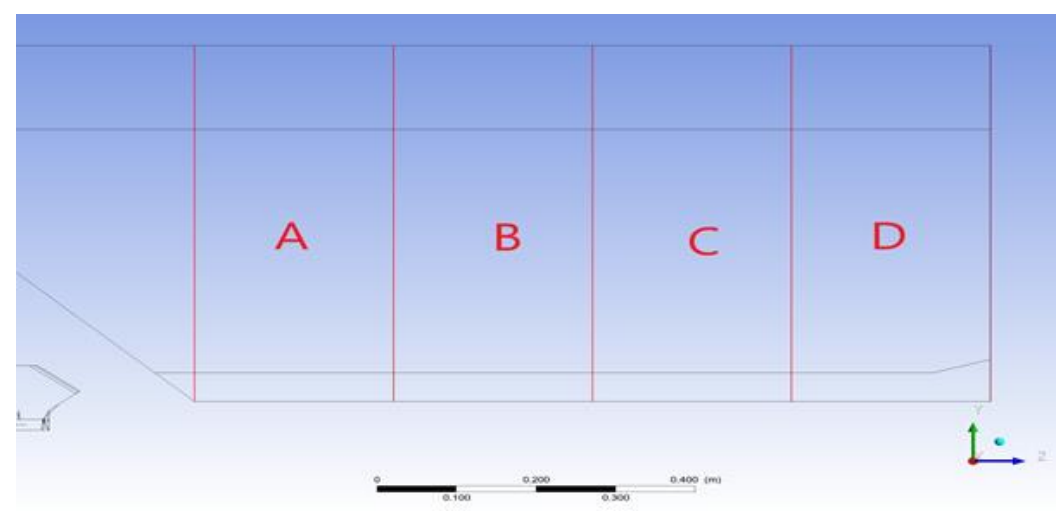

Fig. 7. Divided regions at the downstream segment of dam spillway for scouring determination

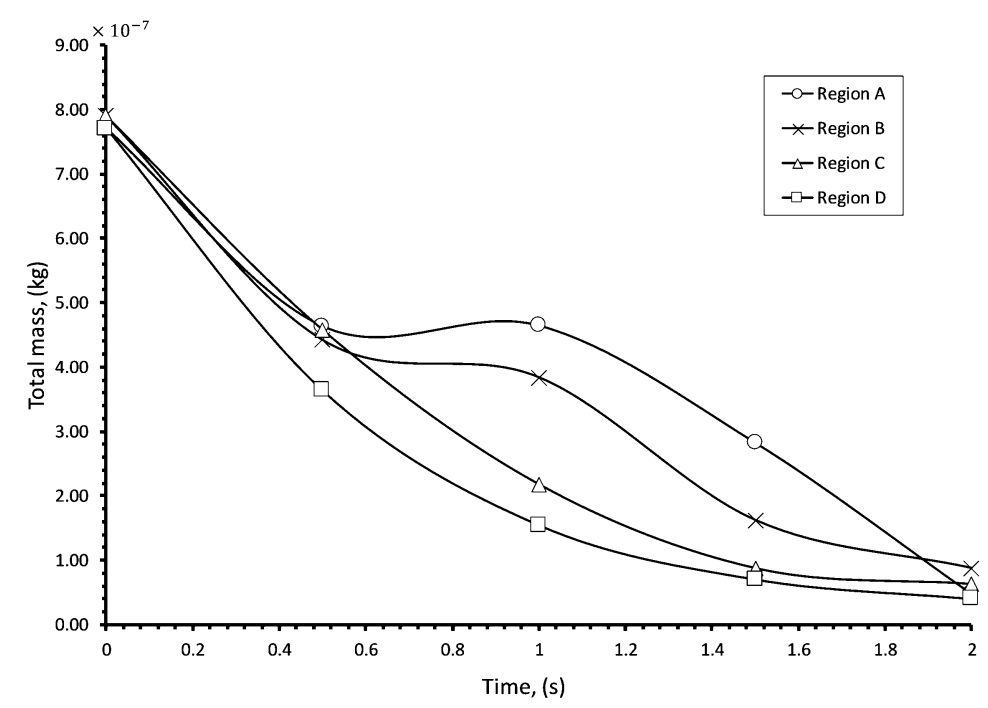

Fig. 8. Plot of total mass over time

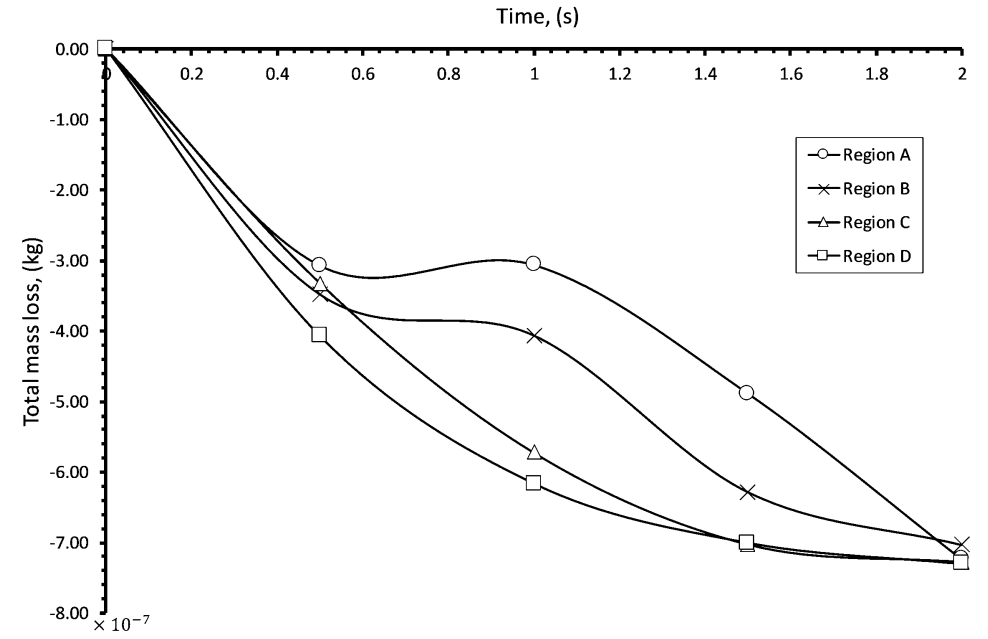

Fig. 9. Plot of total mass loss over time 


\section{Conclusions}

In this paper, the sediment transport and scouring of suspended particles at a spillway dam were numerically simulated using commercially available software, ANSYS. Multiphase volume of fluid (VOF) formulation was adopted to track the flow front of water in the dam spillway, while the movement of suspended sediment particles were tracked based on the discrete phase model (DPM). The simulation findings were in great consensus with the particle image velocimetry experiment using the scaled-down spillway model, with the discrepancy lower than $4.89 \%$. This inferred that the proposed numerical model is correct, and the subsequent numerical findings are acceptable. The spillway flow and sediment particle tracks were presented and discussed. Scouring was visualized in the simulation as there is gradual loss of sediment mass at the bottom of spillway during the spillway flow. The mass loss of sediment particles increasing with time, with the largest scouring rate and deposition rate recorded are respectively $4.20 \times 10^{-9} \mathrm{~kg} / \mathrm{s}$ and $2.00 \times 10^{-6} \mathrm{~kg} / \mathrm{s}$. Generally, the current simulation work suggested the viability of DPM approach in simulating the sediment transport and scouring phenomenon, that emphasizing on the fluid-particle interaction between water and suspended particles.

\section{Acknowledgement}

The authors would like to acknowledge Universiti Tenaga Nasional for providing the facilities and financial assistance under URND TNB fund (U-TG-CR-18-01), UNITEN BOLD GRANT and UNITEN BOLD Refresh Publication Fund.

\section{References}

[1] Zhang, L. M., Y. Xu, and J. S. Jia. "Analysis of earth dam failures: A database approach." Georisk 3, no. 3 (2009): 184189. https://doi.org/10.1080/17499510902831759

[2] Zawawi, Mohd Hafiz, F. C. Ng, Aqil Azman, L. H. Tung, Ismail Abustan, Z. Mohd Remy Rozainy, and Aizat Abas. "Reliability analysis on the reservoir dam spillway structure using fluid-structure interaction." In IOP Conference Series: Materials Science and Engineering, vol. 920, no. 1, p. 012030. IOP Publishing, 2020. https://doi.org/10.1088/1757-899X/920/1/012030

[3] Ng, Fei Chong, Aizat Abas, Ismail Abustan, Z. Mohd Remy Rozainy, M. Z. Abdullah, and Sharon Melissa Kon. "Fluid/structure interaction study on the variation of radial gate's gap height in dam." In IOP Conference Series: Materials Science and Engineering, vol. 370, no. 1, p. 012063. IOP Publishing, 2018. https://doi.org/10.1088/1757899X/370/1/012063

[4] Ng, Fei Chong, Aizat Abas, Ismail Abustan, Z. Mohd Remy Rozainy, M. Z. Abdullah, and Sharon Melissa Kon. "Effect of the gap height of radial gate on the volumetric flow rate in dam." In IOP Conference Series: Materials Science and Engineering, vol. 370, no. 1, p. 012062. IOP Publishing, 2018. https://doi.org/10.1088/1757899X/370/1/012062

[5] Nashurdin, Muhammad Naqib, Aizat Abas, Aqil Azman, F. C. Ng, M. R. M. Radzi, and A. Hassani. "Numerical visualization of flow in spillway and downstream of dam using fluid/structure interaction." In AIP Conference Proceedings, vol. 2129, no. 1, p. 020044. AIP Publishing LLC, 2019. https://doi.org/10.1063/1.5118052

[6] Ng, F. C., Aqil Azman, Aizat Abas, Mohd Hafiz Zawawi, Ahmad Zhafran Ahmad Mazlan, Nazirul Mubin Zahari, and Z. Mohd Remy Rozainy. "Fluid/structure Interaction Numerical Study on the Mechanical Integrity of Water Dam Reservoir Banks." In IOP Conference Series: Materials Science and Engineering, vol. 815, no. 1, p. 012021. IOP Publishing, 2020. https://doi.org/10.1088/1757-899X/815/1/012021

[7] Cui, Yantao, and Andrew Wilcox. "Development and application of numerical models of sediment transport associated with dam removal." Chapter 23 (2008): 995-1020. https://doi.org/10.1061/9780784408148.ch23

[8] Cui, Yantao, Gary Parker, Christian Braudrick, William E. Dietrich, and Brian Cluer. "Dam removal express assessment models (DREAM). Part 1: model development and validation." Journal of Hydraulic Research 44, no. 3 (2006): 291-307. https://doi.org/10.1080/00221686.2006.9521683

[9] Wilcock, Peter R., and Joanna C. Crowe. "Surface-based transport model for mixed-size sediment." Journal of hydraulic engineering 129, no. 2 (2003): 120-128. https://doi.org/10.1061/(ASCE)0733-9429(2003)129:2(120) 
[10] Castillo, Luis G., and José M. Carrillo. "Scour, velocities and pressures evaluations produced by spillway and outlets of dam." Water 8, no. 3 (2016): 68. https://doi.org/10.3390/w8030068

[11] Kitamura, Y., and S. Takagi. "Hydraulic study on scouring downstream of Funagira Dam spillway apron (Japan)." (2016). https://doi.org/10.1201/9781315375045-79

[12] Comiti, F., M. A. Lenzi, and L. Mao. "Local scouring at check dams in mountain rivers." Check dams, morphological adjustments and erosion control in torrential streams. Nova Publ., Hauppauge, NY, USA (2010): 263-82.

[13] Kloss, Christoph, Christoph Goniva, Georg Aichinger, and Stefan Pirker. "Comprehensive DEM-DPM-CFD simulations-model synthesis, experimental validation and scalability." In Proceedings of the seventh international conference on CFD in the minerals and process industries, CSIRO, Melbourne, Australia, pp. 9-11. 2009.

[14] PAStrack, DL Cundall. "A discrete numerical model for granular assembles." Geotechnique 29 (1979): $47-65$. https://doi.org/10.1680/geot.1979.29.1.47

[15] Zahari, N. M., M. H. Zawawi, L. M. Sidek, Daud Mohamad, Zarina Itam, M. Z. Ramli, Agusril Syamsir, Aizat Abas, and M. Rashid. "Introduction of discrete phase model (DPM) in fluid flow: A review." In AIP Conference Proceedings, vol. 2030, no. 1, p. 020234. AIP Publishing LLC, 2018. https://doi.org/10.1063/1.5066875

[16] Ng, Fei Chong, Aizat Abas, Z. L. Gan, Mohd Zulkifly Abdullah, F. Che Ani, and M. Yusuf Tura Ali. "Discrete phase method study of ball grid array underfill process using nano-silica filler-reinforced composite-encapsulant with $\begin{array}{lllll}\text { varying filler } \quad \text { loadings." Microelectronics } & \text { Reliability } 72 & \text { (2017): }\end{array}$ https://doi.org/10.1016/j.microrel.2017.03.034

[17] Ng, Fei Chong, Mohd Hafiz Zawawi, Lun Hao Tung, Mohamad Aizat Abas, and Mohd Zulkifly Abdullah. "Symmetrical Unit-Cell Numerical Approach for Flip-Chip Underfill Flow Simulation." CFD Letters 12, no. 8 (2020): 55-63. https://doi.org/10.37934/cfdl.12.8.5563

[18] Azman, Aqil, Fei Chong Ng, Mohd Hafiz Zawawi, Aizat Abas, Mohd Remy Rozainy MAZ, Ismail Abustan, Mohd Nordin Adlan, and Wei Loon Tam. "Effect of barrier height on the design of stepped spillway using smoothed particle hydrodynamics and particle image velocimetry." KSCE Journal of Civil Engineering 24, no. 2 (2020): 451-470. https://doi.org/10.1007/s12205-020-1605-x

[19] Ng, Fei Chong, Aizat Abas, and Mohd Zulkifly Abdullah. "Effect of solder bump shapes on underfill flow in flip-chip encapsulation using analytical, numerical and PIV experimental approaches." Microelectronics Reliability 81 (2018): 41-63. https://doi.org/10.1016/i.microrel.2017.12.025

[20] Ng, Fei Chong, Aizat Abas, Ismail Abustan, Z. Mohd Remy Rozainy, M. Z. Abdullah, and Sharon Melissa Kon. "Visualization of Underfill Flow in Ball Grid Array (BGA) using Particle Image Velocimetry (PIV)." In IOP Conference Series: Materials Science and Engineering, vol. 370, no. 1, p. 012064. IOP Publishing, 2018. https://doi.org/10.1088/1757-899X/370/1/012064 